\title{
Education for tribal children: An engine for human development
}

\author{
Malyadri, Pacha $\$ \\ Principal, Government Degree College, Osmania University, Andhra Pradesh, India (drpm16@yahoo.com.in)
}

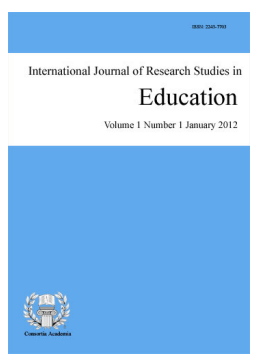

ISSN: $2243-7703$

Accepted: 19 September 2011

\section{Abstract}

The Indian Constitution assigns special status to the Scheduled Tribes (STs). Traditionally referred to as adivasis, vanbasis, tribes, or tribals; STs constitute about $8 \%$ of the Indian population. There are around 573 Scheduled Tribes living in different parts of the country, having their own languages different from the one mostly spoken in the State where they live. There are more than 270 such languages in India. Accordingly to the 2001 census, the tribal population in India is about 67.8 million. The largest number of tribals is in the undivided Madhya Pradesh (16.40 million), followed by Orissa (7 million) and Bihar (6.6 million). However, the largest proportion of tribals in total population is in Mizoram (95\%), followed by Lakshadweep (93\%), Nagaland (88\%), Meghalaya (86\%), and Arunachal Pradesh (64\%). Nine States - Madhya Pradesh, Chattisgarh, Orissa, Jharkhand, Maharashtra, Gujarat, Rajasthan, Andhra Pradesh, and West Bengal; together account for more than four-fifth of the tribal population in India. The term tribe or tribal is not defined anywhere in the Constitution although according to Article 342, ST represents the tribe or tribal communities that are notified by the President. Tribes are not part of the traditional Hindu caste structure. STs in India are more similar to the "indigenous" or "native people" in other parts of the world. Realizing that Scheduled Tribes are one of the most deprived and marginalized groups with respect to education, a host of programs and measures were initiated during the Independence. Elementary education is a priority area in the Tribal sub-plans from the 5th Five Year Plan. Education of ST children is considered important, not only because of the Constitutional obligation but also as a crucial input for the total development of tribal communities. The present paper made an attempt to analyze the problems in the field of Tribal children education and suggest measures for the development of education among the Tribals in Khammam District of Andhra Pradesh state in India. The study reveals that People of the remote area are superstitious and addicted to blind beliefs. Hence, they do not understand the value of education.

Keywords: tribal groups; scheduled tribes; drop-out problem; human values; indigenous education 


\section{Education for tribal children: An engine for human development}

\section{Introduction}

In recent years sustained and high levels of economic growth provide a unique opportunity and momentum for faster social sector development (Sen, 2007). Investing in education plays a key role in meeting the World Bank's social development objectives, which support inclusive growth, social cohesion, and accountability in development (Sen, 2007). Professor Amartya Sen (2007) recently emphasized education as an important parameter for any inclusive growth in an economy. The policies have to focus on inclusive rather than divisive growth strategies. Education also prevails in illiterate societies, where it is imparted orally and by mass behavior. A member of primitive society learns to earn his livelihood, to do good works, to obey spiritual beings and also superstitions etc from the elders of the society and bind by its laws and regulations. These are the education for them. We the modern people do mean "education as reading and writing". This is also true. By modern education a person can able to increase his knowledge and expand his vision and avail the fruits or development (Sen, 2007). Hence modern education can play the role of "Catalyst" in bringing sea changes in the sphere of social, political, economic fields. One of the important reasons for failure of development activities in the society by various developmental agendas is the prevalence of acute illiteracy and ignorance, combined with superstitions among the rural masses (Malyadri, 1990). Hence to ward off economic backwardness, social deprivation spreading of education is regarded as one of the most effective and forward-looking instruments.

The Indian Constitution assigns special status to the Scheduled Tribes (STs). Traditionally referred to as adivasis, vanbasis, tribes, or tribals, STs constitute about $8 \%$ of the Indian population. There are 573 Scheduled Tribes living in different parts of the country, having their own languages different from the one mostly spoken in the State where they live. There are more than 270 such languages in India. Realizing that Scheduled Tribes are one of the most deprived and marginalized groups with respect to education, a host of programs and measures were initiated ever since the Independence. Elementary education is a priority area in the Tribal sub-plans from the 5th Five Year Plan. Education of ST children is considered important, not only because of the Constitutional obligation but also as a crucial input for total development of tribal communities. The present paper made an attempt to analyze the problems in the field of Tribal children education and suggest measures for development of education among the tribals in Khammam District of Andhra Pradesh state in India. On the basis of an empirical study conducted in tribal areas of Khammam district, the following are some of the observations presented.

\section{Profile of Khammam district}

Khammam district is a conglomeration of mosaic culture representing Hindus, Muslims and Christians. There is sizable number of scheduled tribes, who constitutes an integral part of Hindu community The Khammam district has ST population 5, 58,958 which is about $13.29 \%$ of the total tribal population of the state. Out of the total (46) Mandals; an administrative division of some villages, about (29) Mandals are populated by tribals groups like, Koyas, Lambadas, and Kondareddis and about (2) Mandals are partially populated by tribes. The tribal people are still following their own traditions and customs in their social life. There are 2394 primary schools, 598 upper primary schools, 397 high schools in the district. This includes 133 alternative schools and 152 Maabadies; name of the scheme for school developments, in Tribal Sub Plan (TSP) area.

Pre-primary facility is provided to 338 schools by providing early childhood education centers. 700 Anganwadi centers are provided partial support and brought under supervision of the primary schools. The district, which had a population of 812,993 when it was formed, has about 2,562,412 as per 2001 census. The density has grown from 51 to $160 \mathrm{sq}$. km. out of the total population, of the district there are 1,299,245 males and 1,266,167 females. Among them there are about 360,154 SCs 558,958 STs. About $80 \%$ of the population is 
living in villages. The gender ratio is 974 females for every 1000 male population in villages and about 977 females for 1000 males in the urban areas. The child population of the district in the age group of 0-6 years is 337,459. Gender ratio in the child population in the age group 0-6, 968 female in rural areas, while 971 female in urban areas.

\section{Tribal students}

The survey conducted in Khammam districts Andhra Pradesh shows that only $15 \%$ to $40 \%$ tribal children attend the school (Hanumantha, 2006). There are certain important reasons for the drop out problem in the district. The first and most important reason is the prevailing economic backwardness. We know that majority of the people in the district are poor and who spend most of their times in doing small jobs and marginal farming, where children are also taking part. Hence, financial difficulties created major hindrances for them for sending their children for studies. Secondly, ignorance and superstitions play a major setback for spread of education in the district. People of the remote area are superstitious and addicted to blind beliefs. So they do not understand the value of education. Thirdly, a vital reason for the drop out problem of tribal students is their prevailing cultural process and life style, which hardly creates conducive environment for spreading of education. There is no specific Government sanctioned holidays for tribal's of the state to be observed by the educational institution unlike other communities enjoy. Hence tribal students remain absent in the school during their festive occasions, when there is no holiday. For this reason tribal students are lagging behind in studies from their non-tribal counterparts.

Another point for the drop-out problem is health. The poverty of tribal people doesn't permit them to keep clean their home environment. They don't get nutritious food. Hence, tribal children often suffer from illness. The parents could not treat them timely due to economic scarcity. So they suffer for a long period. During suffering the child remains absent from school and after recovering from illness he loses his appetite for study. However there are few other reasons, which may also be responsible for drop-out problem of tribal students (Mehta \& Shepard, 2006; Radhakrishnan, Hanumantha, \& Samby Reddy, 2006).

1. The medium of teaching such as, Telugu language is a foreign language for the tribal children.

2. Non-tribal teachers are posted to schools located at tribal areas, which are not aware of tribal cultural values.

3. Absence of tribal cultural and regional materials in class books.

4. The school environment does not attract the tribal students.

5. Some schools are not having their own buildings.

6. Schools having single teacher.

7. Teachers in interior pockets neglecting in duties.

8. Irregular supply of mid-day meals.

9. Lack of communication facility.

10. Untimely supply of study materials.

There are many other minor reasons for drop out of tribal students. If this type of process will continue and slow progress of literacy rate will prevail then the very purpose of fundamental right to education as per 86th amendment of Constitution will be defeated. The Constitution of India was introduced in 1950 and there was a pious aim to educate all children from the age group of 6 to 14 years by 1965. But it was failed. Government from time to time fixed a target year for achievement of $100 \%$ literacy. Again, the year 2000 was targeted to 
Malyadri, P.

achieve the goal. It was also unsuccessful. About 40 years have already been elapsed since 1965, but the goal is not attained. We have to again wait for at least 150 years to get cent percent result if the progress of tribal education will continue at the present rate (Mehta, 2005).

\section{Teacher related problems}

The following are some of the Teacher related problems observed:

1. The non-tribal teachers adopt an attitude of indifference to tribal languages, traditions, cultures and life-styles. They fail to perceive the human values ingrained in these folk cultures. When they try to impart an education which neglects these human values and culture, they fail to make it interesting for the tribal children.

2. The ideas of the non-tribal teachers about tribal environment and culture are narrow and hollow. For this they fail to cite examples from the surroundings and make the concepts complicated for the tribal students. The in-built creativity of tribal children remains unknown to the teachers.

3. The relationship between teachers, schools and the villagers is quite thin. In tribal villages, villagers have virtually no relationship with the teachers. Teachers do not get any accommodation facility in most of villages, which makes them irregular, which hampers the normal routine of a school. Further, the apathetic attitude of the villagers and their simplicity provide ample scope to the teachers to act according to their will.

4. The appointment of untrained teachers in tribal areas diminishes the values of education. However, recently the Government has started posting trained teachers in tribal schools which is a welcome step.

5. Teachers have a preconception that tribal children are average students; also they don't take special care in promoting tribal education.

6. The pre-conceived notions of the teachers that the tribal children cannot grasp anything beyond nature, forest and agriculture create barriers in expanding primary education among the tribal areas.

7. No special training on tribal languages, cultures or current problems is being imparted to the teachers serving in tribal areas.

8. Children's engagement in household works agriculture coupled with parent's indifference towards their children's studies deprive the teachers to render their services in the classroom.

9. No effort is made on the part of the higher authorities and the tribal masses to curb the frequent absenteeism among the teachers. The lack of a frequent and recurrent inspection mechanism no doubt aggravates the situation.

10. Teachers face wide gulf between the language used in the books and the native uses while teaching the tribal students. They simply opine that the content of the text books is beyond the comprehension of the students, so teaching becomes futile.

\section{Condition of primary schools}

The tribal habitations remain in scattered forms. So, they don't fulfill the needs of the required amount of child population to open a school within $1 \mathrm{~km}$. radius. So, in the tribal areas schools remain far away from the habitations. The number of Ashram schools is scanty. Ashram schools are best fitted for the tribal children. In the primary schools, no effort is made to provide incentives and scope to music, dance, games, paintings, etc. which remains as latent potentialities with a child. 
In a school, a tribal child undergoes mental stress and strain. The school buildings are in broken condition and hence not attractive. Lack of care and repair makes it difficult to sit in the collapsing class rooms. Neither the villagers nor the Sarpanch; democratically elected head of a village level statutory institution of local self-government called the gram panchayat (village government) in India, take any active interest to preserve and protect the school building. They preserve the impression that it is the Government outlook and not theirs. No accommodation arrangement is being made for teachers either in the school or in the village development. Physical barriers and communication difficulties also keep the tribal children away from the schools (Vimala, Mehrotra, \& Jandhyala, 2007).

\section{Study material}

Books are not supplied to the schools at the session beginning by the Tribal Welfare Department and the Text Book Press. This irregularity found in the supply of books creates problems both for the teachers and students. Further, stipends are not given in due time. Further school fails to work out the idea of utilizing the services of the local architects, painters and artists at a low cost to prepare some of the educational kits for the children. The language used in the books is beyond the understanding of the tribal children. Sometimes the local teachers also get swayed way by the bookish language and don't try to communicate in the tribal languages. As a result teaching seems to be artificial for the tribal children. The kits that have been provided to the schools under the Operation Black Board Scheme are not properly utilized by the teachers. The contents of the primary school books are less practice oriented and are more factual and abstract. Teaching at primary schools ignores the local nature, culture and environment.

\section{Social and cultural problems}

The community life, the economy, the life style, the traditions of the Tribals and their outlook of the world is totally unique. All these have got their humanitarian values and cultural significance. But they have not found recognition in the ideas of local inspectors, teachers, parents and policy planners. The root cause of this can be attributed to the stratification system and the tribal and non-tribal attitude. Thus, a strong consciousness and pro-tribal attitude have not been built up among the people. The non-government organizations (NGOs) have no doubt taken some steps in this area. But how far the efforts of the NGOs will be successful in changing the institutionalized practices of society is still doubtful.

The greatest problem is that the Tribals have come to recognize the modernization and the demands of time. But they are not coming forward to bring reforms in the educational status and economic standards. Now a strong campaign is needed for awareness. The voluntary agencies should try to launch this campaign on a long term basis with constructive ideas.

\section{Suggestions}

To achieve the goal of inclusive growth at a short span of time following recommendations may be adopted:

1. Study books must be prepared in tribal language up to upper primary level. Tribal students must be supplied with study materials and dresses free of cost. Every school must be well-equipped with all study materials.

2. Teachers from the same tribe and from the nearby villages if possible from the same village should be appointed. Teachers must be paid regularly with free accommodation facility in school campus. Responsibility may be laid down to teachers for enrollment of all children from the age group of 6 to 14 years and not allow dropouts at any circumstances.

3. Each parent must be motivated to send their children above six years to school or teachers and parents may be legally bound to do this task. The school time table is co-opted with the agricultural and social 
necessities, which will facilitate the parents in economic development and educational development of the child. The parents should also invite the teachers to join in the various festivals organized in the villages.

4. Training at intervals to the Non-tribal teachers about the tribal culture and language should be provided. All NGOs functioning in the district may be involved in the process to educate all Tribal children from 6 to 14 years. A realistic survey should be made in the tribal areas as regards how many children are not coming to schools and about the actual number of schools required

5. Special incentives and allowance should be provided to the teachers working in tribal areas. They should be transferred to plain areas after serving 3/4 years in tribal areas. The teachers should establish a healthy rapport with the tribal students and create a positive environment for them.

\section{Conclusion}

Communal life forms a basic parameter of the tribal society. It finds manifestation through the various festivals and cultural celebrations. If the teachers can participate in these occasions by giving due regards to the tribal culture, then she can build up a good educational centre in the village. In the tribal village, the teacher should be a learner, more specifically a 'seeker' of local knowledge from the tribal culture, which would ultimately turn into a global knowledge. The oral tradition in teaching must be an important device to develop the personality of a tribal child from its own cultural environment, instead of creating an artificial blurred personality dissociated with home and school environment.

To bridge the gap of the socio-cultural environment with that of the school curriculum exploration of rich tribal folklore can be helpful in the promotion of tribal education. These suggestions may be implemented in a war footing manner and all concerned from parents, teachers to Heads of the district must work whole-heartedly to achieve cent percent education to all children from 6 to 14 years within a limited span of time and bring a sea change in their society to bring the tribal in to the mainstream. It may sum up with words of Swami Vivekananda; The only service to be done for our lower classes is to give them education; to develop their lost individuality, give them ideas-that is the only help they require and then the rest must follow as the effect. Ours is to put the chemicals together, crystallization comes in the law of nature. Now if the mountain cannot come to Mohammed, Mohammed must go to the mountain. If the poor boy cannot come to education, education must go to him. This is true and has its relevance till the present day, which may be followed strictly for Human Development.

About the author: Dr. P. Malyadri has got 27 years of experience of Teaching, Research, Administration, Training and consultancy. A prolific writer; Dr. Malyadri has published 4 Books and 58 research papers on Banking, Rural and economic development issues in various National and International journals of repute. He has presented several research papers in around 80 National and International seminars and conferences. He is an active member in Editorial advisory boards of 39 international journals published from Canada, USA, Taiwan, Czech Republic, Italy, Turkey, Dubai, Philippines, Australia, Bangladesh, Romania, Pakistan, Africa, and many others; and 3 national journals of repute. Dr. Malyadri carried out two Major Research Projects sponsored by the UGC, New Delhi.

Dr. P. Malyadri is also a recognized Research supervisor to guide M.Phil. and Ph.D. students in the Departments of Commerce and Business Management, Osmania University and was awarded 2 Ph.D.'s and 22 M.Phil.'s under his guidance. He served as Program officer of the National Service Scheme for 5 years and conducted several programs and received outstanding awards. Presently he is serving as the Principal; Osmania University affiliated college for the last 3 years. He received several outstanding awards for his academic achievements. Dr. Malyadri is State level Best Teacher awardees in the year 2008, honored by Government of Andhra Pradesh. 


\section{References:}

Hanumantha, R. V. (2006). Growth of elementary education: Fifty years of Andhra Pradesh 1956-2006. CHDR, Hyderabad.

Malyadri, P. (1990). Financing tribal development programmes. People's action, July(4), 3-7.

Mehta, A. C. (2005): Elementary education in India - Where do we stand? State Report Cards. New Delhi: NIEPA.

Mehta, A. C., \& Shepard, A. (Eds.) (2006). Chronic poverty and development policy in India. Delhi: Sage Publications.

Radhakrishnan, R., Hanumantha, R., \& Samby Reddy, B. (2006). Extreme and chronic poverty and malnutrition in India: Incidence and determinants. In A. Mehta \& A. Shepard (Eds.), Chronic poverty and development policy in India. Delhi: Sage Publications.

Sen, A. (2007): Development as freedom. Oxford University Press, London.

Vimala, R., Mehrotra, R. \& Jandhyala, K. (2007). Incentives in elementary education. Do they make a difference? Journal of Education Planning and Administration, 11(2), 141-153. 
Malyadri, P. 